Document downloaded from:

http://hdl.handle.net/10251/49304

This paper must be cited as:

Benajes Calvo, JV.; Olmeda González, PC.; Martín Díaz, J.; Carreño Arango, R. (2014). A new methodology for uncertainties characterization in combustion diagnosis and thermodynamic modelling. Applied Thermal Engineering. 71(1):389-399.

doi:10.1016/j.applthermaleng.2014.07.010.

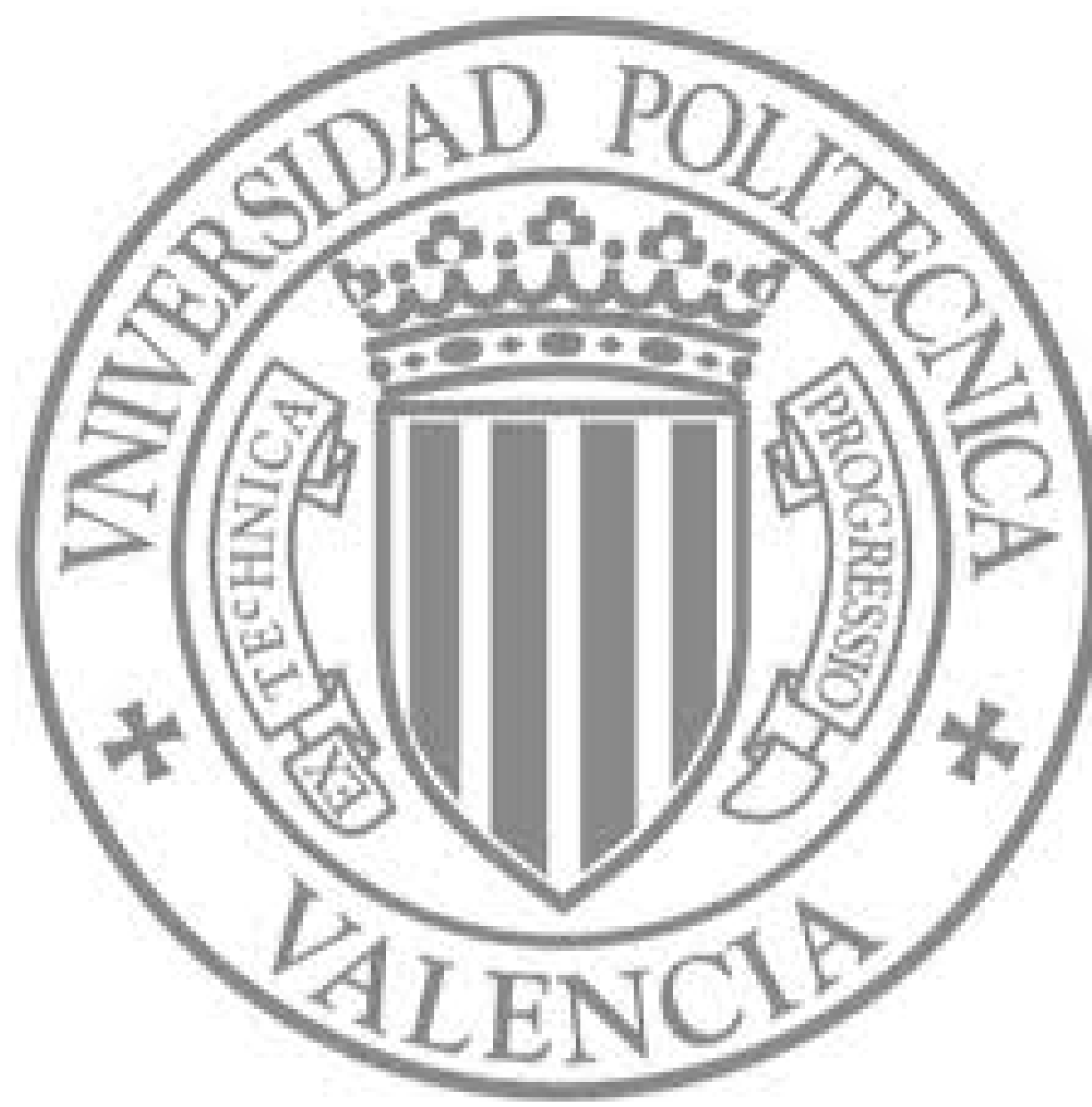

The final publication is available at

http://dx.doi.org/10.1016/j.applthermaleng.2014.07.010

Copyright Elsevier 


\title{
A new methodology for uncertainties characterization in combustion diagnosis and thermodynamic modelling
}

\author{
J. Benajes, P. Olmeda, J. Martín*, R. Carreño \\ CMT-Motores Térmicos, Universitat Politècnica de València, Camino de Vera s/n, 46022, Valencia, Spain
}

\begin{abstract}
Combustion diagnosis based on in-cylinder pressure signals as well as $0 \mathrm{D}$ thermodynamic modelling, are widely used to study and optimize the combustion in reciprocating engines. Both approaches share some uncertainties regarding the sub-models and the experimental installation that, for the sake of accuracy, must be reduced as much as possible in order to obtain reliable results. A methodology, based on the sensitivity effect of such uncertainties on heat release and simulated pressure, is proposed to adjust their values. The methodology is capable of identifying the separate influence of each parameter and to provide a set of values thanks to the Multi-Variable linear regression (MLR) in motoring conditions. The method is flexible enough to deal with different number of uncertainties and can be applied to different engines and thermodynamic models. The final results of the adjustment is validated in combustion conditions, showing an improvement of the apparent combustion efficiency of about $7 \%$ with respect to the reference values.
\end{abstract}

Keywords: Combustion diagnosis, Thermodynamic modelling, Heat transfer, Pressure modelling, Heat release, Uncertainties adjustment

${ }^{*}$ Corresponding author. Tel: +34963877650 ; fax: +34963877659

Email address: jaimardi@mot.upv.es (J. Martín)

$U R L$ : www.cmt.upv.es (J. Martín) 


Abbreviation
\[ \begin{array}{ll}\text { ACE } & \text { Apparent combustion efficiency } \\ B B D C & \text { Before Bottom dead centre } \\ \text { BTDC } & \text { Before Top dead centre } \\ C I & \text { Compression ignition } \\ I C E & \text { Internal Combustion Engine } \\ M L R & \text { Multi-variable Linear Regression } \\ S I & \text { Spark ignition } \\ S O I & \text { Start of injection } \\ T D C & \text { Top dead centre }\end{array} \]

Nomenclature 


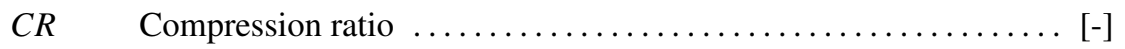

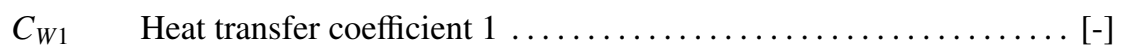

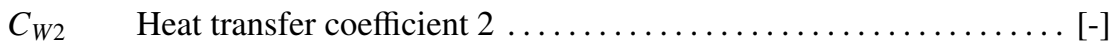

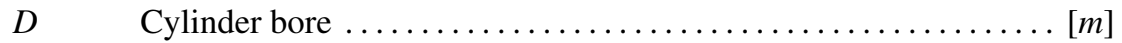

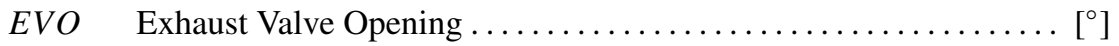

$h \quad$ Heat transfer coefficient $\ldots \ldots \ldots \ldots \ldots \ldots \ldots \ldots \ldots \ldots \ldots \ldots \ldots \ldots \ldots \ldots$

$h_{f, i n j} \quad$ Specific enthalpy of the injected fuel $\ldots \ldots \ldots \ldots \ldots \ldots \ldots[\mathrm{J} / \mathrm{kg}]$

$H R \quad$ Heat Released $\ldots \ldots \ldots \ldots \ldots \ldots \ldots \ldots \ldots \ldots \ldots \ldots \ldots \ldots \ldots \ldots \ldots \ldots$

imep Indicated Mean Effective Pressure $\ldots \ldots \ldots \ldots \ldots \ldots \ldots \ldots$ bar $]$

IVC Intake Valve Closing $\ldots \ldots \ldots \ldots \ldots \ldots \ldots \ldots \ldots \ldots \ldots \ldots \ldots \ldots$

$k_{\text {def }} \quad$ Deformation coefficient $\ldots \ldots \ldots \ldots \ldots \ldots \ldots \ldots \ldots \ldots \ldots \ldots \ldots \ldots \ldots \ldots \ldots$

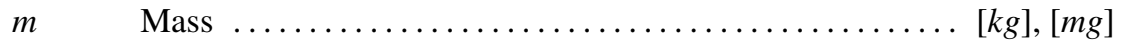

$\dot{m} \quad$ Mass flow rate $\ldots \ldots \ldots \ldots \ldots \ldots \ldots \ldots \ldots \ldots \ldots \ldots \ldots \ldots \ldots \ldots \ldots \ldots$

$n \quad$ Engine speed $\ldots \ldots \ldots \ldots \ldots \ldots \ldots \ldots \ldots \ldots \ldots \ldots \ldots \ldots \ldots \ldots \ldots \ldots$

$p \quad$ In-cylinder pressure $\ldots \ldots \ldots \ldots \ldots \ldots \ldots \ldots \ldots \ldots \ldots \ldots \ldots \ldots \ldots \ldots \ldots \ldots$

$p_{\max } \quad$ Maximum in-cylinder pressure $\ldots \ldots \ldots \ldots \ldots \ldots \ldots \ldots \ldots \ldots \ldots \ldots \ldots$

$p_{\text {ref }} \quad$ Reference pressure $\ldots \ldots \ldots \ldots \ldots \ldots \ldots \ldots \ldots \ldots \ldots \ldots \ldots \ldots$ bar $]$

$Q \quad$ Heat transferred to the combustion chamber walls $\ldots \ldots \ldots \ldots \ldots[J]$

$R \quad$ Specific gas constant of the charge $\ldots \ldots \ldots \ldots \ldots \ldots \ldots[\mathrm{J} / \mathrm{kgK}]$

RoHR Rate of Heat Released $\ldots \ldots \ldots \ldots \ldots \ldots \ldots \ldots \ldots \ldots \ldots \ldots \ldots \ldots \ldots \ldots \ldots \ldots$

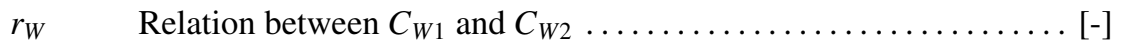

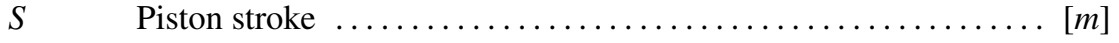

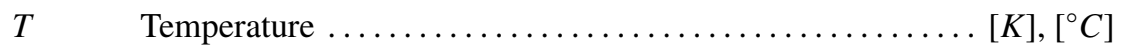

$u_{f, g} \quad$ Internal energy of the evaporated fuel $\ldots \ldots \ldots \ldots \ldots \ldots[\mathrm{J} / \mathrm{kgK}]$

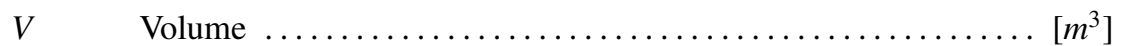

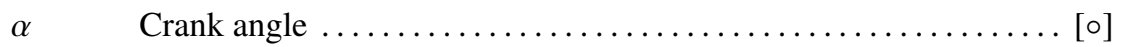

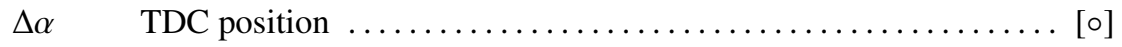




\section{Introduction}

To fulfil the more and more stringent regulations of ICE, a well understanding of combustion process is essential, thus some researchers efforts have been aimed at improving both combustion diagnosis and predictive modelling.

Although there are many methods for combustion diagnosis based on different experimental variables such as exhaust pressure [1] or block vibration [2], in-cylinder pressure is the most reliable variable for combustion diagnosis, through the determination of the rate of heat released (RoHR) [3]. It has been widely used in recent works for different applications such as analysing the effect of fuel blends or catalyst $[4,5,6,7]$, developing NOx models based on RoHR aimed to control [8], or assessing the effect of different injection strategies on the engine performance, emissions and noise reduction [9].

On the other hand, thermodynamic predictive models are useful to obtain pressure and temperature evolution in the combustion chamber, allowing to estimate engine operation features in different applications such as engine design, control and performance prediction $[10,11,12,13,14]$. Moreover, they provide the boundary conditions for detailed combustion or emission models $[15,16,17]$ with a high computational efficiency.

Combustion diagnosis and thermodynamic modelling can be seen as "opposite" methods [18]: in the first case, starting from pressure, the RoHR is obtained thus providing information of combustion development [19]; in the second case, if accurate RoHR is available (using a physical $[15,16,17]$ or empirical $[10,20]$ combustion model), they provide an estimation of the pressure and temperature evolution in a determined operating condition. They have in common the thermodynamic processes in the chamber and the sub-models required for their determination. Different approaches range from simple models such as net heat release calculation [3] or pressure simulation based on isentropic $p V^{n}$ evolution, to detailed analysis including blow-by, fuel injection, gas properties depending on temperature and composition, accurate heat transfer model, etc. [10, 21, 22, 23, 24].

The results of the thermodynamic analysis are affected by some uncertainties due to the sub-models imperfections and the inacuracy of their fitting constants determination. On the other hand, some engine parameters, such as compression ratio may require to be determined. Several works dealing with the effect of such uncertainties and proposals to determine them can be found in the literature. A brief description includes:

- Pressure pegging: the different methods for its determination $[25,26,27,28]$ can be grouped in two categories: experimental methods based on the estimation of the reference pressure on the basis of an experimental measurement [27], or using thermodynamic methods such as the simulation of the polytropic evolution of the gas during the compression stroke in combustion tests or the compression and expansion stroke in motoring test 
[28].

- Compression ratio: it is the main geometric uncertainty and affects the instantaneous volume calculation and thus the gas properties [29]. Klein [30, 31] evaluated four methods for the CR determination by comparing the real compression process with polytropic evolutions. Striker [32] proposed a methodology in which available sensors of production engines, a high gain observer and a volumetric efficiency model were combined. Lapuerta [33] used characteristic geometrical points to adjust CR with a symmetry criterion.

- Engine deformations: the piston and connecting rod are slightly deformed due to the gas pressure in the chamber and the inertial forces. In general, its effect on engine performance or RoHR calculation uses to be smaller than the CR effect [29]. In previous works [10, 29] the authors used a simple model to determine the clearance variations taking into account the pressure and the inertial effects. Aronsson $[34,35]$ used a similar model in an optical engine, and measured the variation of the piston position by means of an optical window in the liner.

- Heat transfer model fitting: a large amount of works dealing with the heat transfer in reciprocating engines can be found in the literature, being most of them focused on the heat transfer to the walls due to convection. Some of the most widespread proposals for heat transfer coefficient are based on the well-known Woschni [36], Annand [37] or Hohenberg [28] formulations. Nowadays, each author carries out a tuning process for a specific engine, based on experimental measurements or thermodynamic assumptions [38, 39, 40, 41, 42, 43], in order to adapt the models to one specific engine.

- TDC position: it can be obtained by means of experimental techniques [44, 45, 46] or thermodynamic methods. The last ones allow determining the angular interval $(\Delta \alpha)$ between the TDC and the trigger, on the basis of the effect of $\Delta \alpha$ on some variables such as heat release [22], simulated pressure [31] or entropy [47]. In this work, the TDC is determined based on the Hohenberg proposal [28].

The stated uncertainties have a different effect on the results but in general they are all relevant for the thermodynamic analysis in the chamber. Although different approaches for the determination of one uncertainty have been presented, there are very few works dealing with the adjustment of several of them at the same time while taking into account the cross effects. This work is aimed at describing a global methodology for adjusting different uncertainties at the same time, separating their specific effects. The proposal is based on the thermodynamic analysis in motoring conditions, thus the effect of the uncertainties in the compression and expansion strokes can be assessed using the 
apparent RoHR and the experimental and simulated pressure comparison. The methodology is based on the minimization of the errors in the RoHR calculation and in the pressure simulation. Although it has been developed using some specific sub-models, it is flexible enough to be used with different models and different engines.

The method has been developed for a multi-cylinder CI engine in motoring conditions and then the suitability of it application in combustion tests is assessed. As it will be shown, the available information is limited in these conditions, thus affecting the performance of the method. The validation of the adjustment is carried out through the combustion analysis at several operation conditions.

\section{Methodology}

The estimation of one parameter can be affected by the incorrect value of other uncertainties that are simultaneously adjusted. Moreover, a combination of parameters can provide a low residual, according to one criteria, but not so good with other one. For example, the effect of an incorrect pressure pegging and CR have similar effect in terms of simulated peak pressure, but they are quite different in term of heat release [29]. Thus, a methodology for determining simultaneously all the uncertainties (taking into account their specific effects) and considering more that one criteria, is recommendable to ensure accuracy.

The schema of the proposed process is shown in Fig. 1. It can be split in three main phases: The first deals with the adjustment of engine characteristics (CR, deformation and heat transfer models). In a second phase and after the adjustment of the heat transfer, $\Delta \alpha$ is calculated using the Hohenberg proposal [28]. Finally, the third phase is aimed to the pressure pegging (different for each test). The processes during the first and third steps are similar, and can be summarised as follows:

1. Starting from a reference set of values, a sensitivity study is carried out to determine the effect during the closed cycle of each uncertainty (see section 5). The effect is analysed in terms of in-cylinder pressure and the error in the RoHR. In the first case the simulated pressure is compared with the experimental one, in the second case, a value different from zero is due to incorrect uncertainties values. The result of this step is the instantaneous evolution of the characteristic effects of each uncertainty in a set of motoring tests.

2. Using the information provided by the previous step, a minimization of the difference between real and simulated pressure and RoHR residuals is performed. For that, a Multi-variable Linear Regression (MLR) [48] is carried out as explained in section 6, thus obtaining a new set of values for the engine characteristics and new references for the pressure signals pegging.

As the effect of each parameter on pressure evolution and RoHR residuals can be slightly different for different values of the other parameters, an iterative process is performed until the variation of all the parameters, in comparison 
with the previous iteration, becomes negligible.

The ROHR is calculated with CALMEC [29] and the pressure is calculated with the thermodynamic predictive model SICICLO [10]. Both of them are in-house developed tools which are briefly explained in section 4.

The result of the process is the optimal set of engine characteristics, ready to be used in the combustion analysis or cycle simulation, along with the pegged in-cylinder pressure in the motoring tests. Although these pressure signals will not be used any more, it is important to highlight that the correct pressure level is required to adjust correctly the rest of uncertainties.

\section{Experimental setup}

For the development and validation of the method, the experimental tests were carried out in a DI Diesel engine, whose main characteristics are given in Table 1. The schema of the test cell layout with the instrumentation for the engine is shown in Fig. 2.

The engine is directly coupled to an electric dynamometer that allows controlling the speed and torque. The in-cylinder pressure was measured with a Kistler 6055B glow-plug transducer with a range between 0 and 250 bar, and a sensitivity of $18.8 \mathrm{pC} / \mathrm{bar}$. The pressure sensor was calibrated according to the usual method proposed in [49]. The electrical charge yielded by the piezoelectric transducers is converted into a voltage signal by means of a Kistler 5011B charge amplifier. A $0.5^{\circ}$ sampling interval was used for the angle-synchronous acquisition of the in-cylinder pressure, which was performed using a Yokogawa DL708E oscillographic recorder with a 16 bits A/D converter module.

The mean variables required were measured at a low sample frequency of $100 \mathrm{~Hz}$, using an AVL tests system. It collects the measurement signals of the different sensors and controls the electric dynamometer.

\section{Thermodynamic model}

Although the methodology has been developed with CALMEC [29] and SICICLO [10], it can be applied to other diagnosis and predictive models, with the only condition that they share the sub-models and hypotheses. Detailed description of these tools can be found in the stated references, being the main hypotheses the following:

- Chamber pressure and temperature are assumed to be spatially uniform. 
- Ideal gas law is used to calculate gas temperature.

- A filling and emptying model is used to calculate the trapped mass [50].

- The specific heat of the gas depends on both temperature and composition [21].

- Blow-by model is based on the evolution of the gas in an isentropic nozzle [10].

- The chamber volume deformation is calculated by means of a simple deformation model [29]:

$$
\Delta V=k_{d e f}\left(\Delta V_{p}+\Delta V_{i}\right)
$$

where $k_{d e f}$ is a deformation constant to be adjusted, and $\Delta V_{p}$ and $\Delta V_{i}$ are the volume variations due to pressure and inertia efforts respectively.

- Heat transfer to the chamber walls is calculated with a modified Woschni-like model [38], where the convective heat transfer coefficient is calculated using Eq. (2):

$$
h=C D^{-0.2} p^{0.8} T^{-0.53}\left[C_{W 1} c_{m}+C_{W 2} c_{u}+C_{2} \frac{V_{d} T_{I V C}}{V_{I V C} p_{I V C}}\left(p-p_{0}\right)\right]^{0.8}
$$

where $C$ and $C_{2}$ are constants whose values are 0.12 and $0.001, c_{m}$ is the mean piston speed, $c_{u}$ is the instantaneous tangential velocity of the gas in the chamber (see [38] for a detailed description of this term), $p_{0}$ is the pressure in motoring conditions assuming a polytropic evolution, and $C_{W 1}$ and $C_{W 2}$ are constants, whose values must be adjusted for each engine. The ratio $r_{w}$ between $C_{W 1}$ and $C_{W 2}$ was assumed to take a constant value of 1.7 [18], therefore both constants are obtained at the same time. Since the method is developed in motoring conditions, the last term in Eq.(2) (accounting for the pressure variations due to combustion) is zero, and the expression can be written as follows:

$$
h=C D^{-0.2} p^{0.8} T^{-0.53} C_{W 1}^{0.8}\left[c_{m}+c_{u} / 1.7\right]^{0.8}
$$

In order to adjust the heat transfer and deformation models in a specific engine, $C_{W 1}$ and $k_{d e f}$ must be adjusted simultaneously with CR.

\section{Sensitivity study}

By solving the first law of thermodynamics, the following expression for RoHR can be obtained [18]: 


$$
\operatorname{RoHR}=\frac{\mathrm{d} H R}{\mathrm{~d} \alpha}=m c_{v} \frac{\mathrm{d} T}{\mathrm{~d} \alpha}+\frac{\mathrm{d} Q}{\mathrm{~d} \alpha}+p \frac{\mathrm{d} V}{\mathrm{~d} \alpha}-\left(h_{f, i n j}-u_{f, g}\right) \cdot \frac{\mathrm{d} m_{f, e v}}{\mathrm{~d} \alpha}+R T \frac{\mathrm{d} m_{b b}}{\mathrm{~d} \alpha}
$$

where $m$ and $c_{v}$ are the mass and specific heat, $h_{f, i n j}$ and $u_{f, g}$ are the injected fuel enthalpy and the evaporated fuel internal energy and $R, \mathrm{~d} m_{f, e v}, \mathrm{~d} m_{b b}$ are the ideal gas constant, the variation of fuel injected and blow-by leakage respectively. In motoring conditions, the RoHR is zero, however Eq. (4) can provide a non-zero value $\left(\varepsilon^{R o H R}\right)$ due to the uncertainties. In this conditions Eq.(4) leads to the following expression:

$$
\varepsilon^{R o H R}=m c_{v} \mathrm{~d} T+\mathrm{d} Q+p \mathrm{~d} V+R T \mathrm{~d} m_{b b}
$$

SICICLO calculates the simulated motoring pressure by solving Eq.(5) for $p$, assuming that $\varepsilon^{R o H R}=0$, thus obtaining:

$$
p_{s i m}=-\frac{m c_{v} \mathrm{~d} T+d Q+R T \mathrm{~d} m_{b b}}{\mathrm{~d} V}
$$

The determination of the predictive model results uncertainty is straightforward through the differentiation of experimental and simulated pressures.

$$
\varepsilon^{p}=p_{\text {sim }}-p_{\text {real }}
$$

Although some experimental error and signal noise can affect $\varepsilon^{R o H R}$, it is assumed that the averaging of the 25 measured cycles and the filtering process reduce the signal noise sufficiently. It is also assumed that all the relevant uncertainties have been considered, and any additional effect on $\varepsilon^{R o H R}$ is due to random experimental uncertainties.

As stated, the identification of the specific effect of each parameter is a key issue to ensure their independence, and to assess the characteristic behaviour of each uncertainty. Fig. 3 shows the effect of the parameters variation presented in Table 2 on $\varepsilon^{R o H R}$ (left) and $\varepsilon^{p}$ (right), where the variation range is taken from a previous study [18].

The main conclusions of the sensitivity study are:

- CR: a CR increment leads to a lower combustion chamber volume. Although CR does not affect $\mathrm{d} V$, it modifies $\mathrm{T}$ through the application of the ideal gas law, thus affecting the specific heat and the heat transfer term in Eq.(5). The main effect of CR on $\varepsilon^{R o H R}$ (Fig.3a) is due to the variation of $\mathrm{d} T$ in the internal energy term, that can be expressed as $\mathrm{d} T=-\frac{(n-1) p \mathrm{~d} V+T \mathrm{~d}(m R)}{m R}$, being $n=-\frac{\mathrm{d} p / p}{\mathrm{~d} V / V}$ the politropic exponent. The CR affects $n$, producing the asymmetric behaviour of $\varepsilon^{R o H R}$. Its effect is higher in the proximities of TDC, where the variation of the chamber volume has a higher relative effect. On the other hand, a higher CR leads to a higher simulated pressure and thus a positive $\varepsilon^{p}$ as shown in Fig.3f. 
- $K_{d e f}$ : the $k_{d e f}$ affects the volume calculation, and hence the temperature and the politropic exponent, however, its effect is qualitatively different from CR. Whilst the CR change produces an error in the volume that remains constant during all the cycle, deformations depend on pressure and acceleration, thus their effect vary during compression and expansion, being more important near TDC (see Fig. 3b and g), where the pressure reaches its maximum value. On the other hand, the higher the load, the higher the effect of the deformations, therefore $\varepsilon^{R o H R}$ and $\varepsilon^{p}$ will change slightly at different operation points.

- $C_{W 1}$ : the higher this constant is, the higher the heat transfer becomes. In Eq.(5) it is possible to see that the heat transfer uncertainty is directly transferred to $\varepsilon^{R o H R}$, as can be seen in Fig. 3c. Contrary to CR and $k_{d e f}$, the error in $C_{W 1}$ has almost a symmetric effect on RoHR, being more important as the pressure and temperature increase. The effect on $\varepsilon^{p}$ shows the opposite trend than $\varepsilon^{R o H R}$, because a less adiabatic evolution of the gas leads to a lower simulated pressure, as shown in Fig. 3h. The symmetry in Fig. 3h is not perfect due to the fact that the variation of the heat transfer during the compression stroke is not compensated in the expansion stroke.

- TDC: the thermodynamic gap between the peak pressure and TDC depends on the heat transfer [23], thus TDC position determination $\Delta \alpha$ cannot be considered independent of $C_{W 1}$. However, for the sake of completeness, it is interesting to analyse its effect on RoHR. The variation of $\Delta \alpha$ leads to different $p$ and $d p$ for a determined $\alpha$, which results in errors in the work, $T$ and $d T$, and thus in the heat transfer and the internal energy variation. The combination of these effects produces the $\varepsilon^{R o H R}$ shown in Fig. 3d. As $p_{\text {real }}$ in Eq.(7) slightly affected by the variation of $\Delta \alpha$, the effect on Fig. 3i is produced by the small change in the IVC pressure, and mostly by the change of $p_{\text {real }}$ for each crank angle.

- $p_{\text {ref }}$ : it has two main effects: on the one hand it leads to temperature and specific heat variations, on the other hand, the pressure variation results in uncertainties in the politropic exponent and hence in the work estimation. The pegging pressure affects the whole compression and expansion strokes, being its effect on $\varepsilon^{R o H R}$ higher far from TDC (see Fig. 3e), because the relative effect is smaller when the cylinder pressure increases. In contrast, the effect on $\varepsilon^{p}$ is more important near the TDC (see Fig. 3j), because a small variation of the pressure level at IVC is amplified during the compression.

\section{Uncertainties determination based on Multiple Lineal Regression}

Starting from the characteristic effects determined in the previous section, and assuming the hypothesis of linearity [18], the total error in RoHR $\varepsilon_{u n}^{R o H R}$ and simulated pressure $\varepsilon_{u n}^{p}$ due to the uncertainties can be expressed as: 


$$
\begin{gathered}
\varepsilon_{u n}^{R o H R}(\alpha) \simeq c_{1} \varepsilon_{C R}^{R o H R}(\alpha)+c_{2} \varepsilon_{C_{w 1}}^{R o H R}(\alpha)+c_{3} \varepsilon_{K_{d e f}}^{R o H R}(\alpha)+c_{4} \varepsilon_{P_{r e f}}^{R o H R}(\alpha) \\
\varepsilon_{u n}^{p}(\alpha) \simeq c_{1} \varepsilon_{C R}^{p}(\alpha)+c_{2} \varepsilon_{C_{w 1}}^{p}(\alpha)+c_{3} \varepsilon_{K_{\text {def }}}^{p}(\alpha)+c_{4} \varepsilon_{P_{r e f}}^{p}(\alpha)
\end{gathered}
$$

where $\alpha$ is the crank angle, $\varepsilon_{C R}, \varepsilon_{C_{w 1}}, \varepsilon_{K_{d e f}}$ and $\varepsilon_{P_{r e f}}$ are the effect of the uncertainties variation on RoHR and pressure residuals, and $c_{1}$ to $c_{4}$ are weighting constants. The mathematical expressions for $\varepsilon^{R o H R}$ and $\varepsilon^{p}$ are similar, thus Eq.8 and Eq.9 can be written as:

$$
\varepsilon_{u n, i}(\alpha)=\sum_{j=1}^{m} c_{j} \varepsilon_{u n, i, j}(\alpha)
$$

where $\varepsilon_{u n, i}$ is the error in RoHR or $p$ produced by the $m$ uncertainties considered at the operating point $i . \varepsilon_{u n, i, j}$ is the specific error produced by the uncertainty $j$ in the operating point $i$, and $c_{j}$ the corresponding weighting constant. Note that the possibility of including additional uncertainties (in case of using other sub-models) is implicitly considered. The equation system Eq.(10) can be solved by knowing $m$ equations, however, as a pressure signal has $n>>m$ samples, Eq.(10) is an over determined equation system that must be solved in order to minimize $\varepsilon^{R o H R}$ and $\varepsilon^{p}$ during the closed cycle. This is done by means of Multi-variable Linear Regression (MLR) taking into account the considered parameters, whose optimal solution is found by means of the least square method. For a determined operation point $i$, the instantaneous error in the RoHR or simulated pressure $\left(\varepsilon_{\text {exp }, i}\right)$ can be expressed as:

$$
\varepsilon_{\text {exp }, i}(\alpha)=\varepsilon_{u n, i}(\alpha)-\varepsilon_{\text {res }, i}(\alpha)
$$

where $\varepsilon_{r e s, i}$ accounts for the effect of the terms not considered specifically with the stated uncertainties, such as some experimental uncertainties or signal noise. In order to diminish the residual, a swept of engine speed was considered in motoring conditions, taking into account several cycles, so that the addition of the error in RoHR or simulated pressure in all tests at a defined crank angle will be:

$$
\sum_{i=1}^{t e s t s} \varepsilon_{\text {exp }, i}(\alpha)=\sum_{i=1}^{t e s t s} \varepsilon_{u n, i}(\alpha)-\sum_{i=1}^{t e s t s} \varepsilon_{r e s, i}(\alpha)
$$

Taking into account the differentiation between engine characteristics and pressure pegging described in section 2, Eq.(12) can be written as:

$$
\sum_{i=1}^{t e s t s} \varepsilon_{\text {exp }, i}(\alpha)=\sum_{j=1}^{m-1} \sum_{i=1}^{\text {tests }} c_{j} \varepsilon_{u n, i, j}(\alpha)+\sum_{i=1}^{t e s t s} c_{i} \varepsilon_{p_{\text {ref }, i}}(\alpha)-\sum_{i=1}^{t e s t s} \varepsilon_{r e s, i}(\alpha)
$$

On the one hand, the error due to the neglected uncertainties and noise is aleatory, therefore the addition of different operation points compensates it, being $\varepsilon_{r e s}(\alpha) \approx 0$. On the other hand, as described in section 2 , p pef is adjusted for each operating point in a second phase after the engine characteristic adjustment, therefore it can be assumed that after a number of iteration $\sum_{i=1}^{t e s t} c_{i} \varepsilon_{p_{\text {ref }, i}} \approx 0$ in Eq.(13), thus: 


$$
\sum_{i=1}^{\text {tests }} \varepsilon_{\text {exp }, i}(\alpha)=\sum_{j=1}^{m-1} \sum_{i=1}^{\text {tests }} c_{j} \varepsilon_{\text {un }, i, j}(\alpha)
$$

If Eq.(14) is written for each crank angle, the following matrix is obtained:

$$
\left[\begin{array}{c}
\sum_{i=1}^{\text {tests }} \varepsilon_{\text {exp }, i}\left(\alpha_{1}\right) \\
\sum_{i=1}^{\text {tests }} \varepsilon_{\text {exp }, i}\left(\alpha_{2}\right) \\
\vdots \\
\sum_{i=1}^{\text {tests }} \varepsilon_{\text {exp }, i}\left(\alpha_{n}\right)
\end{array}\right]=\left[\begin{array}{ccc}
\sum_{i=1}^{\text {tests }} \varepsilon_{i, 1}\left(\alpha_{1}\right) & \ldots & \sum_{i=1}^{\text {tests }} \varepsilon_{i, m-1}\left(\alpha_{1}\right) \\
\sum_{i=1}^{\text {tests }} \varepsilon_{i, 1}\left(\alpha_{2}\right) & \ldots & \sum_{i=1}^{\text {tests }} \varepsilon_{i, m-1}\left(\alpha_{2}\right) \\
\vdots & & \vdots \\
\sum_{i=1}^{\text {tests }} \varepsilon_{i, 1}\left(\alpha_{n}\right) & \ldots & \sum_{i=1}^{\text {tests }} \varepsilon_{i, m-1}\left(\alpha_{n}\right)
\end{array}\right]\left[\begin{array}{c}
c_{1} \\
c_{2} \\
\vdots \\
c_{m-1}
\end{array}\right]
$$

The solution of this matrix results in a set of correction parameters $c_{1}, c_{2}, \ldots c_{m-1}$, that weight the effect of each specific uncertainty on the RoHR or simulated pressure errors. The iterative process is carried out by applying the following correction at each step:

$$
P_{j, k}=P_{j, k-1}+c_{j, k} \Delta P_{j}
$$

Where $P_{j, k}$ is the estimation of the $P_{j}$ parameter $\left(C R, K_{d e f}\right.$ and $\left.C_{W 1}\right)$ in the $k$ iteration, $c_{j, k}$ is the correction factor obtained by the MLR in the $k$ iteration, and $\Delta P_{j}$ is the variation of each parameter in the sensitivity study as detailed in Table 2. The procedure can be performed only in one step, however it was checked that the process provides more accurate results when an iterative process is used, due to the fact that the effect of each uncertainty on $\varepsilon^{R o H R}$ and $\varepsilon^{p}$ can vary slightly depending on its value. It was found that after the third iteration, the variation of the parameters is lower than $1 \%$, which was assumed to be an acceptable variation.

Since both the effect of RoHR and simulated pressure are considered, the process is carried to find the optimal values that minimize separately $\varepsilon^{R o H R}$ and $\varepsilon^{p}$. Finally the optimal values are averaged.

\section{Results and discussion}

\subsection{Adjustment with motoring tests}

The operating points used for this study are shown in Table 3. Three repetitions of each operating point were measured and the average results are presented. The initial values of the parameters to be adjusted are shown in the "reference" column of Table 4. The initial TDC position was assumed to be at the peak pressure in motoring conditions, the initial CR value is the one provided by the engine manufacturer, $k_{d e f}$ is the average value obtained in several engines used in a previous work [18], and $C_{W 1}$ is the value proposed by Woschni [36]. The pressure pegging was initially carried out assuming that the pressure at the BDC coincides with the pressure at the inlet manifold. It was 
checked that the final values provided by the proposed method do not depend on the initial values, however, they must lie in an limited range around the actual value, so that the hypothesis of linear and independent behaviour of the effect is accomplished. If the initial values are too far from the actual ones, the iterative method can provide results with no physical meaning or not converge at all. In both cases the problem can be detected.

The values of the parameters adjusted are presented in the "motoring" column of Table 4 . The errors obtained with the initial and the adjusted parameters are shown in Table 5, where the RMSE of $\varepsilon^{R o H R}$ and the difference between the modelled and measured peak pressure are shown. The difference between the initial TDC position and the adjusted value is $0.9^{\circ}$. This phase gap uses to be longer in smaller engines because they use to be less adiabatic as Hohenberg reported [23]. It is interesting to highlight the importance of the TDC position correction provided by the method. Indeed, assuming that TDC is located at the peak pressure would lead to imep errors that only can be admissible at full load. However, a deviation of $0.5^{\circ}$ at mid load could lead to imep errors about 3\% [29] and much higher at low load. The CR correction obtained with the method is 0.1 . This variation leads, in the worst case, to a deviation in the simulated peak pressure of about 3 bar. This error can increase in the case of combustion simulation where the inlet pressure will be higher. Regarding $k_{d e f}$, the correction obtained is \pm 0.9 with respect to the reference value. Although having a lower effect than $C R$, the effect of this correction can lead to variations in the volume at the TDC about $2 \%$ at full load, where the high pressure produces important deformations. The uncertainty in the volume would directly affect the in-cylinder temperature calculation thus affecting the RoHR (in the combustion diagnosis) and the pressure evolution (in case of thermodynamic simulation). Finally, the $C_{W 1}$ correction, 0.54 , can produce a maximum variation of the heat transfer peak in combustion about $14 \%$, leading to 3 bar error in the peak pressure in motoring conditions (higher in combustion). The effect of the heat transfer change on cumulated HR can reach 1-2\% of the fuel energy at low speed and load, where the heat transfer to the chamber walls is about one third of the fuel energy [51].

As shown in Table 5, the adjusted parameters provide a lower error in the two observed variables in almost all the operating conditions. Since the method optimizes the global results, for the sake of the accuracy in most of the operating conditions slightly worse results can be obtained in some specific tests. Thus, the RoHR at $1000 \mathrm{rpm}$ shows a higher residual than that obtained with the original values. For the sake of brevity the analysis is presented for one engine, however the method showed similar trends in other Diesel engines tested. As seen in Table 5, the performance of the method is even better if the simulated pressure is considered: the difference between the simulated and experimental peak pressure diminishes from $9 \%$ to less than $1 \%$ after the adjustment.

In order to evidence the effect of the adjustment on the instantaneous evolution of a compression cycle, Fig. 4 shows $\varepsilon^{R o H R}$ and $\varepsilon^{p}$ in four motoring tests used for the adjustment. The mid frequency oscillations of $\varepsilon^{R o H R}$ due to the signal noise remain in $\varepsilon^{R o H R}$, but they are centred around zero because the low frequency deviation, due to incorrect parameters, are almost completely removed. In the case of $\varepsilon^{p}$ the pressure error is clearly reduced. 


\subsection{Adjustment with late SOI tests}

Once the methodology was developed and tested in motoring conditions, the viability to be applied in combustion tests, with late SOI, was evaluated. The main potential advantage of using combustion tests instead of motoring tests is the similar thermal and thermodynamic conditions (gas and wall temperatures, pressure and gas composition) with respect to the nominal combustion tests. The main drawback is the smaller crank angle slot in which the thermodynamic analysis can be applied: about half the duration than in motoring conditions, because it can be applied only between IVC and SOI.

The result of the test carried out are presented in Fig.5, where the behaviour of the errors during the compression are in agreement with those described for the motoring test, having an important reduction in both $\varepsilon^{R o H R}$ and $\varepsilon^{p}$. However, despite the good performance in the reduction of the instantaneous errors, the values of $C R, C_{W 1}$ and $k_{d e f}$ obtained (see "late SOI 1" column in Table 4), are not in agreement with that obtained in motoring conditions. This difference can be explained through the observation of the sensitivity effects shown in Fig.3: when comparing the effect of each uncertainty, they have a similar trend up to $-20^{\circ}$ BTDC and is in the range $\pm 20^{\circ}$ where the characteristic behaviour of each parameter is more evident. As only some part of these region is available for the analysis, the method can not differentiate correctly their effects, thus providing results that adjust reasonably the compression stroke but that are not coherent. Hence, it can be stated that if the information of the complete closed cycle (or at least most of it) is not available, the assumption of independent effects is not fulfilled and the method does not work properly. According to this results it can be concluded that the use of the late SOI is not useful to adjust all the uncertainties at the same time. Taking into account this limitation, the method was tested for determining only the CR. This can be a convenient solution taking into account that $C_{W 1}$ and $k_{d e f}$ are parameters that remain constant during the engine life and do not change for different cylinders. Thus, if they were obtained previously using a set of motoring tests, the TDC position could be obtained knowing the heat transfer, and the CR could be determined with the proposed method. This can be useful if the chamber geometry is modified. As shown in "late SOI 2" column in Table 4, the method performs properly and the $\mathrm{RC}$ value is the same than that obtained in motoring conditions.

\subsection{Combustion validation and results}

In order to validate the performance of the method, the apparent combustion efficiency (ACE), defined as the ratio between the maximum cumulated heat release and the total energy of the fuel, was analysed in a set of combustion tests. The ACE can be seen as a control parameter that provides an assessment of the models and measurement global accuracy. In case of complete combustion, its value is always slightly different from $100 \%$, ranging ideally $100 \pm 2 \%$, 
and usually $100 \pm 5 \%$. Fig.6 shows the ACE of a complete speed and load sweep, where the nearly complete combustion was corroborated by the low $\mathrm{CO}$ an $\mathrm{HC}$ values. It is possible to see that after the adjustment, the ACE is clearly better than using the original parameter: the mean values is 101\%, indicating a good accuracy of the models, and an improvement of $8 \%$ with respect to the initial values. The cumulated HR obtained in both cases, at four operating conditions, is shown in Fig.7. It can be stated that the HR is overestimated with the initial parameters, being the high $C_{W 1}$ and the incorrect TDC position the main reasons of this error, because their effect is not compensated during the compression-expansion strokes (see Fig. 3).

For the sake of brevity the analysis is completed only with two additional parameters. Thus, Figs. 8 and 9 show the difference of the indicated efficiency and peak temperatures calculated with the adjusted and the initial parameters in the complete engine map. On the one hand, it can be seen that the initial parameters (mainly TDC position) lead to overestimating the indicated efficiency more than $4 \%$ at low load, where the maximum error take place. On the other hand the variations of the peak temperature is a key parameter for both the thermal behaviour of the engine, and NOx formation. As shown, the maximum variations reach $57^{\circ} \mathrm{C}$ at high load, being the relative effect more important at low speed. This variation can lead to heat transfer errors up to $9 \%$. Moreover, in case that the chamber conditions were used as boundary condition for a combustion model, this variation would have important effect on NOx modelling.

\section{Conclusions}

It has been shown that different uncertainties (CR, TDC position, heat transfer model constant $-C_{W 1^{-}}$, deformation model constant $-k_{d e f}$ - and pressure pegging) can affect the results of the thermodynamic analysis in both combustion diagnosis and cycle simulation. Taking into account the necessity of adjusting all of them simultaneously, a global methodology has been proposed. It is based on the identification of the characteristic effect of each parameter on the RoHR and the simulated pressure. The method follows an iterative procedure which allows calculating the optimal set of parameters that minimises both RoHR and a simulated pressure errors in motoring conditions, using the Multi-Variable Linear Regression. Although the method is developed for a multi-cylinder DI Diesel engine and some specific sub-models, it is flexible enough to be used with different ones.

The analysis is completed with the evaluation of the method when it is applied to combustion operation with late SOI. It was found that the adjustment in motoring condition is a stable process but when the adjustment is carried out with late combustion, the reliability of the process is limited due to the smaller angular slot available to apply the thermodynamic analysis. In this case only the CR can be determined, if the other uncertainties have been previously adjusted. 
The method allows reducing the RMSE of RoHR error between $20 \%$ and $70 \%$ and the error in the maximum pressure modelled from 9 to $1 \%$ for the tested engine. The performance of the adjusted parameters is validated through the combustion analysis in which the heat release and the apparent combustion efficiency was analysed, obtaining a global improvement of about $7 \%$ of the fuel energy with respect to reference values, with a final residual of about $1 \%$. Finally, the effect of the new engine characterisation is analysed in terms of indicated efficiency and gas temperature variation, showing a variation in the first case higher to $4 \%$ and in the second case higher than $50^{\circ} \mathrm{C}$.

\section{Ackowledgments}

The support of the Generalitat Valenciana (BEST/2010/145) is greatly acknowledged.

\section{References}

[1] O. Chiavola, S. Conforto, Exhaust pressure signal for automotive engines diagnosis, SAE Technical Paper Series 2001-01-3198 (2001).

[2] F. Taglialatela-scafati, M. Lavorgna, Use of Vibration Signal for Diagnosis and Control of a Four-Cylinder Diesel Engine, SAE Technical Paper Series 2011-24-0169 (2011).

[3] J. B. Heywood, Internal Combustion Engine Fundamentals, McGraw-Hill, New York, USA, 1988.

[4] O. Armas, R. Ballesteros, M. D. Cardenas, Thermodynamic diagnosis of diesel and biodiesel combustion processes during load-increase transient sequences, Applied Energy 97 (2012) 558-568 doi:10.1016/j.apenergy.2011.12.058.

[5] C. Guido, C. Beatrice, P. Napolitano, Application of bioethanol/RME/diesel blend in a Euro5 automotive diesel engine: Potentiality of closed loop combustion control technology, Applied Energy 102 (2013) 13-23 doi:10.1016/j.apenergy.2012.08.051.

[6] B. Tompkins, H. Song, J. Bittle, T. Jacobs, Efficiency considerations for the use of blended biofuel in diesel engines, Applied Energy 98 (2012) 209-218 doi:10.1016/j.apenergy.2012.03.025.

[7] R. K. Maurya, A. K. Agarwal, Experimental study of combustion and emission characteristics of ethanol fuelled port injected homogeneous charge compression ignition (HCCI) combustion engine, Applied Energy 88 (4) (2011) 1169-1180 doi:10.1016/j.apenergy.2010.09.015.

[8] C. Guardiola, J. López, J. Martín, D. García-Sarmiento, Semiempirical in-cylinder pressure based model for NOX prediction oriented to control applications, Applied Thermal Engineering 31 (2011) 3275-3286 doi:10.1016/j.applthermaleng.2011.05.048.

[9] A. Torregrosa, A. Broatch, A. García, L. Mónico, Sensitivity of combustion noise and NOx and soot emissions to pilot injection in PCCI Diesel engines, Applied Energy 104 (2013) 149-157. doi:10.1016/j.apenergy.2012.11.040.

[10] F. Payri, P. Olmeda, J. Martín, A. García, A complete 0D thermodynamic predictive model for direct injection diesel engines, Applied Energy 88 (12) (2011) 4632-4641 doi:10.1016/j.apenergy.2011.06.005.

[11] E. Weißenborn, T. Bossmeyer, T. Bertram, Adaptation of a zero-dimensional cylinder pressure model for diesel engines using the crankshaft rotational speed, Mechanical Systems and Signal Processing 25 (6) (2011) 1887-1910 doi:10.1016/j.ymssp.2010.08.016.

[12] B. Maass, R. Stobart, In-Cylinder Pressure Modelling with Artificial Neural Networks, SAE Technical Paper (2011) doi:10.4271/2011-011417.

[13] Y. Shen, J. Bedford, I. S. Wichman, Thermodynamic modeling of direct injection methanol fueled engines, Applied Thermal Engineering 29 (11-12) (2009) 2379-2385 doi:10.1016/j.applthermaleng.2008.12.002.

[14] D. Descieux, M. Feidt, One zone thermodynamic model simulation of an ignition compression engine, Applied Thermal Engineering 27 (8-9) (2007) 1457-1466 doi:10.1016/j.applthermaleng.2006.10.002.

[15] J. Arrègle, J. López, J. García, C. Fenollosa, Development of a zero-dimensional Diesel combustion model. Part 1: Analysis of the quasisteady diffusion combustion phase, Applied Thermal Engineering 23 (11) (2003) 1301-1317 doi:10.1016/S1359-4311(03)00079-6.

[16] J. Arrègle, J. López, J. Garcí, C. Fenollosa, Development of a zero-dimensional Diesel combustion model Part 2: Analysis of the transient initial and final diffusion combustion phases, Applied Thermal Engineering 23 (11) (2003) 1319-1331 doi:10.1016/S1359-4311(03)00080-2. 
[17] J. Arrègle, J. J. López, J. Martín, E. M. Mocholí, Development of a Mixing and Combustion Zero- Dimensional Model for Diesel Engines, SAE Technical Paper Series 2006-01-1382 (2006).

[18] J. Martín, Diagnóstico de la combustión en motores de Diesel de inyección directa, Reverté, Barcelona, 2012. ISBN: 978-84-291-4717-9

[19] J. Serrano, F. Arnau, V. Dolz, P. Piqueras, Methodology for characterisation and simulation of turbocharged diesel engines combustion during transient operation. Part 1: Data acquisition and post-processing, Applied Thermal Engineering 29 (1) (2009) 142-149 doi:10.1016/j.applthermaleng.2008.02.011.

[20] J. Serrano, H. Climent, C. Guardiola, P. Piqueras, Methodology for characterisation and simulation of turbocharged diesel engines combustion during transient operation. Part 2: Phenomenological combustion simulation, Applied Thermal Engineering 29 (1) (2009) 150-158 doi:10.1016/j.applthermaleng.2008.02.010.

[21] M. Lapuerta, O. Armas, J. J. Herna, Diagnosis of DI Diesel combustion fromin-cylinder pressure signal by estimation of mean thermodynamic properties of the gas, Applied Thermal Engineering 19 (5) (1999) 513-529 doi:10.1016/S1359-4311(98)00075-1.

[22] P. Tunestål, TDC Offset Estimation from Motored Cylinder Pressure Data based on Heat Release Shaping, Oil \& Gas Science and TechnologyRevue d'IFP Energies nouvelles 66 (4) (2011) 705-716 doi:10.2516/ogst/2011144.

[23] G. Hohenberg, Definition und Eigenschaften des thermodynamischen Verlustwinkels von Kolbenmaschinen, Automobil-Industrie 4 (1976) $15-21$.

[24] C. D. Rakopoulos, G.M. Kosmadakis, A.M. Dimaratos, E. G. Pariotis, Investigating the effect of crevice flow on internal combustion engines using a new simple crevice model implemented in a CFD code, Applied Energy 88 (1) (2011) 111-126 doi:10.1016/j.apenergy.2010.07.012.

[25] K. Lee, M. Yoon, M. Sunwoo, A study on pegging methods for noisy cylinder pressure signal, Control Engineering Practice 16 (8) (2008) 922-929 doi:10.1016/j.conengprac.2007.10.007.

[26] F. Payri, J. Luján, J. Martín, A. Abbad, Digital signal processing of in-cylinder pressure for combustion diagnosis of internal combustion engines, Mechanical Systems and Signal Processing 24 (2010) 1767-1784 doi:10.1016/j.ymssp.2009.12.011.

[27] W. Brown, Methods for evaluating requirements and errors in cylinder pressure measurement, SAE Paper 670008.

[28] G. Hohenberg, Experimentelle Erfassung der Wandwarme in Kolbenmotoren, Ph.D. thesis, Technical University of Graz,Graz, Austria (1980).

[29] F. Payri, S. Molina, J. Martín, O. Armas, Influence of measurement errors and estimated parameters on combustion diagnosis, Applied Thermal Engineering 26 (2-3) (2006) 226-236 doi:10.1016/j.applthermaleng.2005.05.006.

[30] M. Klein, A Specific Heat Ratio Model and Compression Ratio Estimation, Licentiate thesis, Linköping University (2004).

[31] M. Klein, L. Eriksson, J. Åslund, Compression ratio estimation based on cylinder pressure data, Control Engineering Practice 14 (3) (2005) 197-211 doi:10.1016/j.conengprac.2005.03.022.

[32] K. Stricker, L. Kocher, E. Koeberlein, D. V. Alstine, G. M. Shaver, Estimation of Effective Compression Ratio for Engines Utilizing Flexible Intake Valve Actuation, Journal of Automobile Engineering (2011).

[33] M. Lapuerta, O. Armas, S. Molina, Study of the compression cycle of a reciprocating engine through the polytropic coefficient, Applied Thermal Engineering 23 (3) (2003) 313-323 doi:10.1016/S1359-4311(02)00193-X.

[34] U. Aronsson, Processes in Optical Diesel Engines, Ph.D. thesis, Lund University (2011).

[35] U. Aronsson, Impact of Mechanical Deformation Due to Pressure, Mass, and Thermal Forces on the In-Cylinder Volume Trace in Optical Engines of Bowditch Design, SAE Technical paper 2011-26-008 (2011).

[36] G. Woschni, A Universally Applicable Equation for the Instantaneous Heat Transfer Coefficient in the Internal Combustion Engine, SAE Technical Paper Series 670931.

[37] W. Annand, Heat transfer in the cylinders of reciprocating internal combustion engines, Proc. Inst. Mech. Engrs. 177 (1963) $973-990$.

[38] F. Payri, X. Margot, A. Gil, J. Martín, Computational Study of Heat Transfer to the Walls of a DI Diesel Engine, SAE paper 2005-01-0210 (2005).

[39] F. Payri, X. Margot, A. Gil, J. Martín, Prediction of heat transfer to the walls in DI Diesel engines, Proceedings of the 2nd EACC.

[40] N. Komninos, G. Kosmadakis, Heat transfer in HCCI multi-zone modeling: Validation of a new wall heat flux correlation under motoring conditions, Applied Energy 88 (5) (2011) 1635-1648 doi:10.1016/j.apenergy.2010.11.039. 
[41] H. Soyhan, H. Yasar, H. Walmsley, B. Head, G. Kalghatgi, C. Sorusbay, Evaluation of heat transfer correlations for HCCI engine modeling, Applied Thermal Engineering 29 (2-3) (2009) 541-549 doi:10.1016/j.applthermaleng.2008.03.014.

[42] P. Tunestål, Self-tuning gross heat release computation for internal combustion engines, Control Engineering Practice 17 (4) (2009) 518-524 doi:10.1016/j.conengprac.2008.09.012.

[43] A. Sanli, A. N. Ozsezen, I. Kilicaslan, M. Canakci, The influence of engine speed and load on the heat transfer between gases and in-cylinder walls at fired and motored conditions of an IDI diesel engine, Applied Thermal Engineering 28 (11-12) (2008) 1395-1404 doi:10.1016/j.applthermaleng.2007.10.005.

[44] T. Yamanaka, M. Esake, M. Kinoshita, Mesurement of TDC in engine by microwave technique, IEEE transactions MTT-33 (12).

[45] H. Angström, Cylinder pressure indicating with multiple transducer, accurate TDC evaluationg, zero levels and analysis of mechanical vibrations, 3 Internationales Indiziersymposium (1998) 103-108.

[46] R. Hampel, D. Kurr, H. Schefenaker, Elektronisches zur digitalen Erfassung und Auswertung von Indikatordiagrammen, MTZ 36 (2).

[47] M. Tazerout, O. L. Corre, S. Rousseau, TDC Determination in IC Engines Based on the Thermodynamic Analysis of the Temperature-Entropy Diagram, SAE Technical paper 1999-01-1489 (1999).

[48] S. Weisberg, Applied Linear Regressions, 3rd Edition, John Wiley \& Sons, 2005.

[49] J. Tichý, G. Gautschi, Elektrische Meßtechnik, Springer, Berlin, 1980

[50] F. Payri, J. Galindo, J. Martín, F. J. Arnau, A Simple Model for Predicting the Trapped Mass in a DI Diesel Engine, SAE Technical Paper Series 2007-01-0494 (2007).

[51] F. Payri, P. Olmeda, J. Martin, R. Carreño, A New Tool to Perform Global Energy Balances in DI Diesel Engines, SAE Int. J. Engines 7 (1) (2014) doi:10.4271/2014-01-0665. 


\section{Figures}

Figure 1. Adjustment procedure.

Figure 2.Test cell schema.

Figure 3.Sensitivity study, left: $\varepsilon^{R o H R}$, rigth: $\varepsilon^{p}$.

Figure $4 . \varepsilon^{R o H R}$ (left) and $\varepsilon^{p}$ (right) for the motoring measurement.

Figure 5. $\varepsilon^{R o H R}$ (left) and $\varepsilon^{p}$ (right) for the late SOI test.

Figure 6.ACE of a set of combustion measurements using the initial and the adjusted parameters.

Figure 7.Cumulative HR with the initial parameters and the adjusted ones.

Figure 8.Indicated efficiency comparison between initial and adjusted parameters.

Figure 9.Maximum temperature deviations using initial and adjusted parameters. 


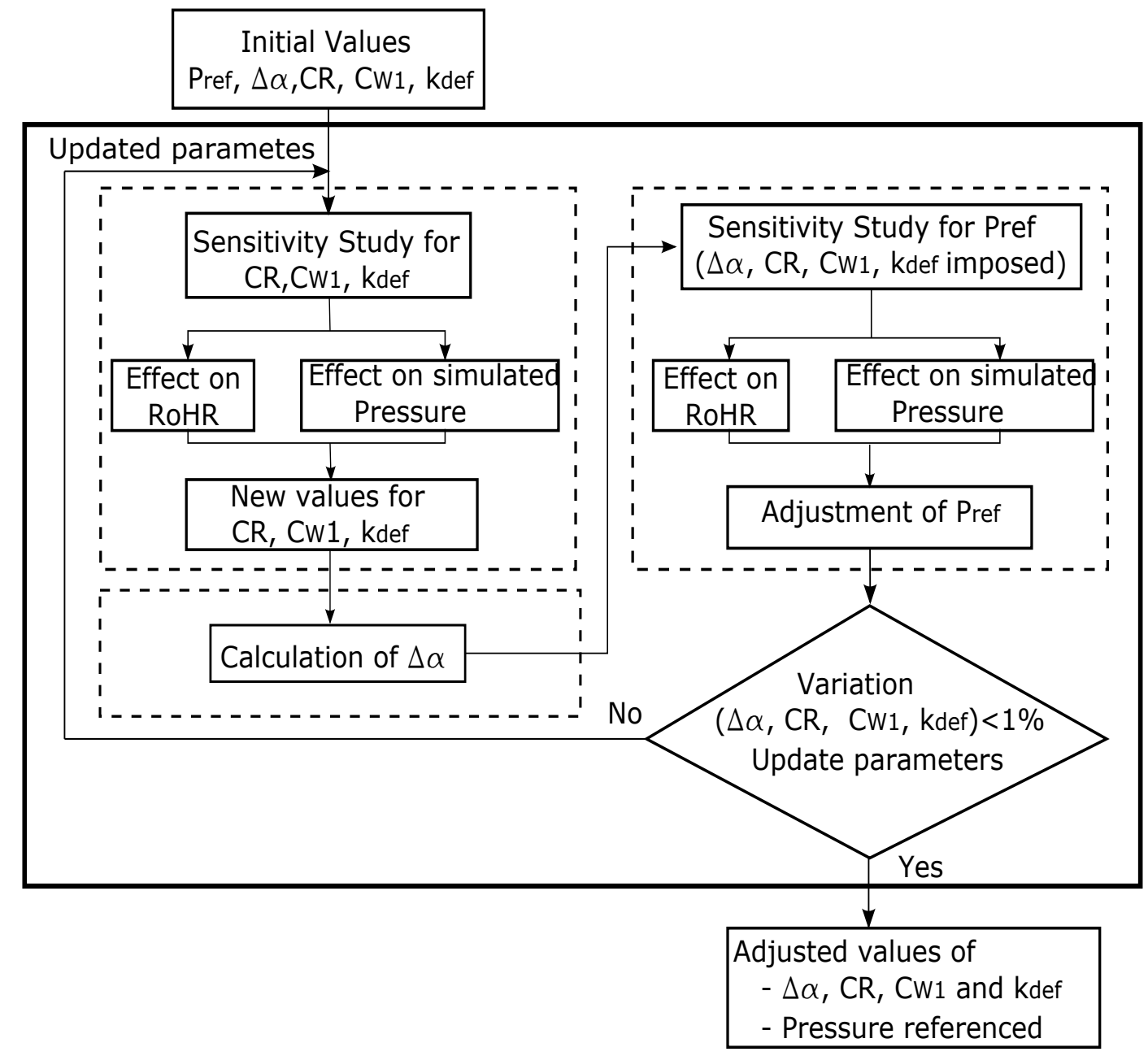

Figure 1: Adjustment procedure 


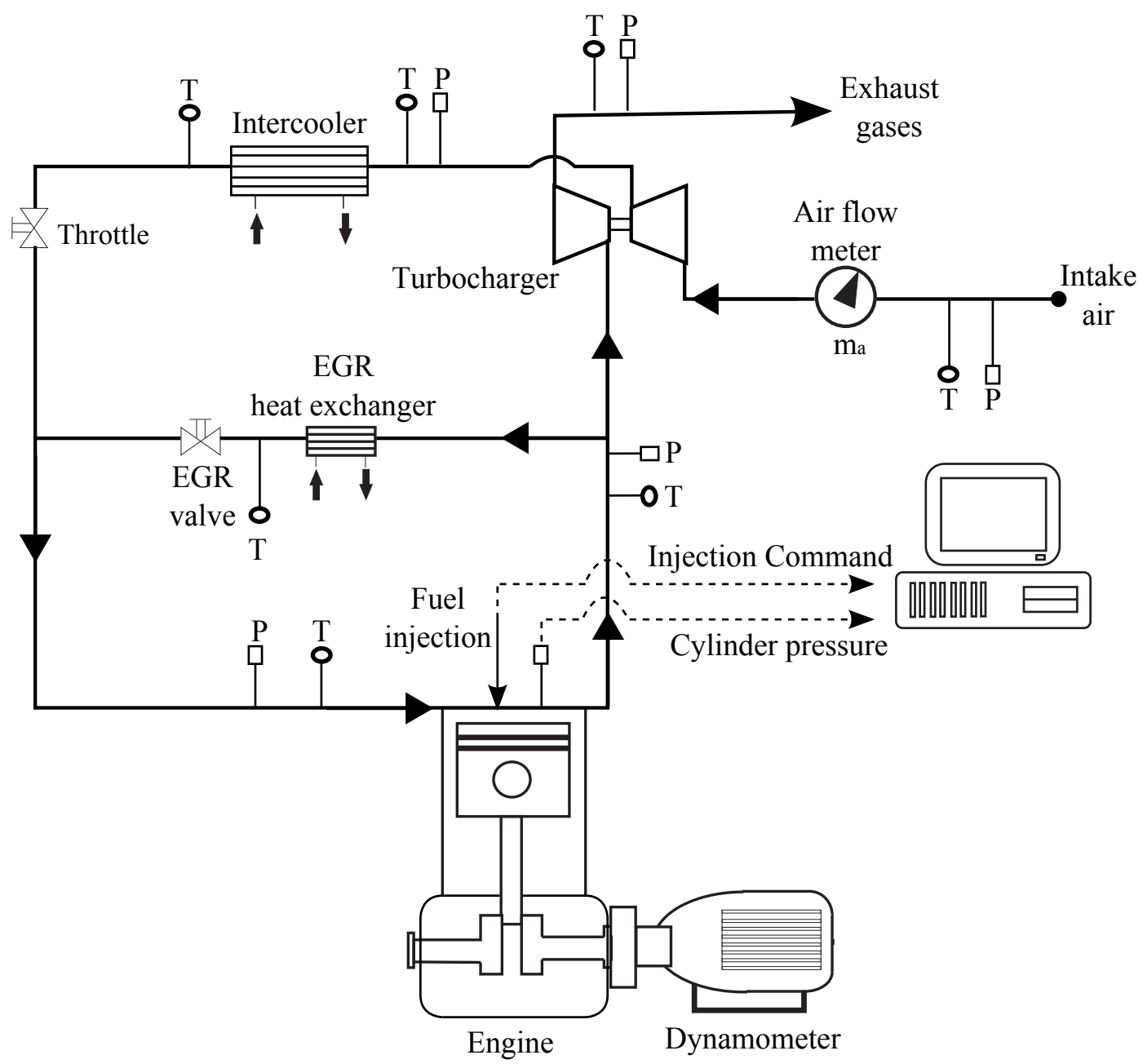

Figure 2: Test cell schema 

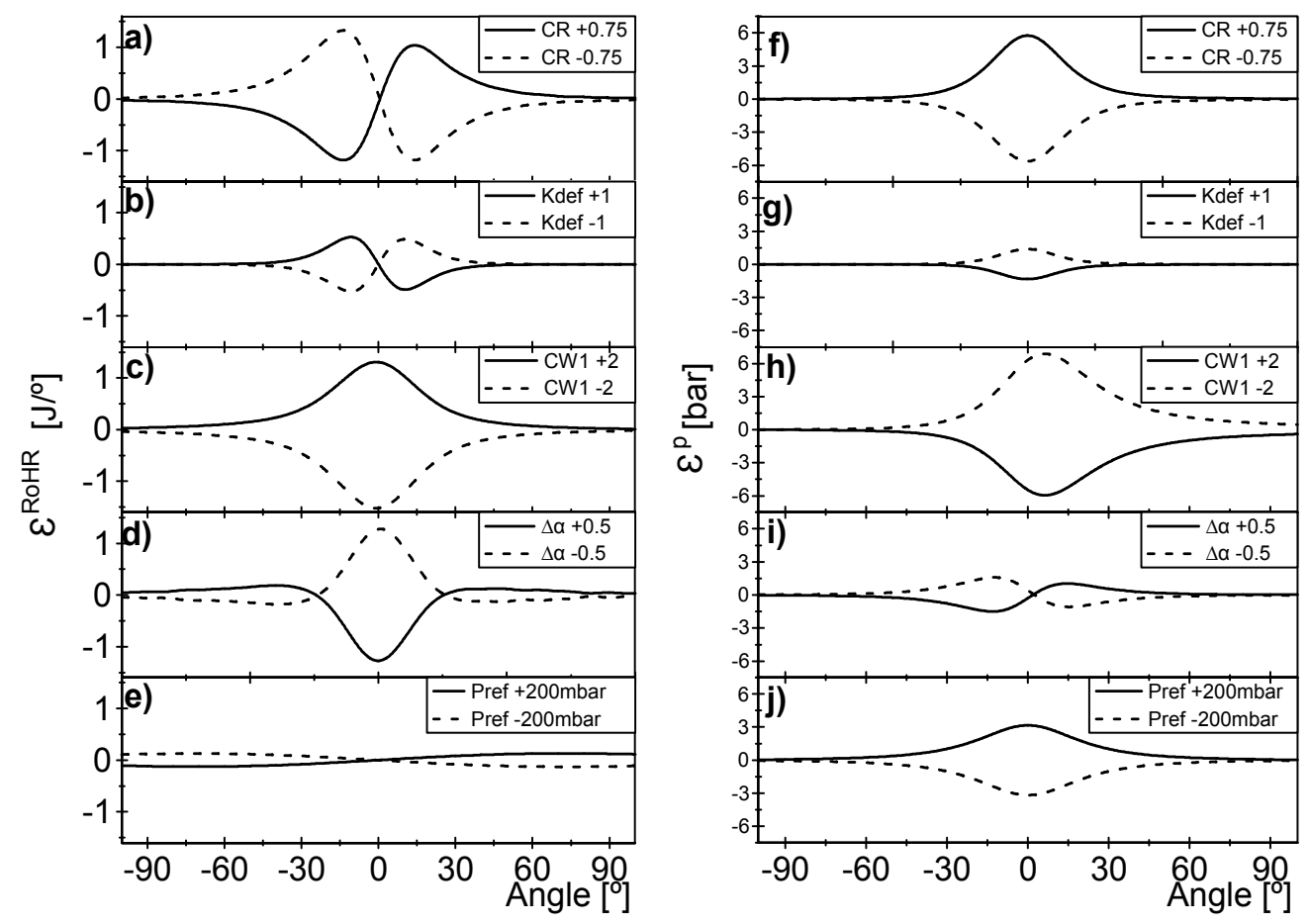

Figure 3: Sensitivity study, left: $\varepsilon^{R o H R}$, rigth: $\varepsilon^{p}$
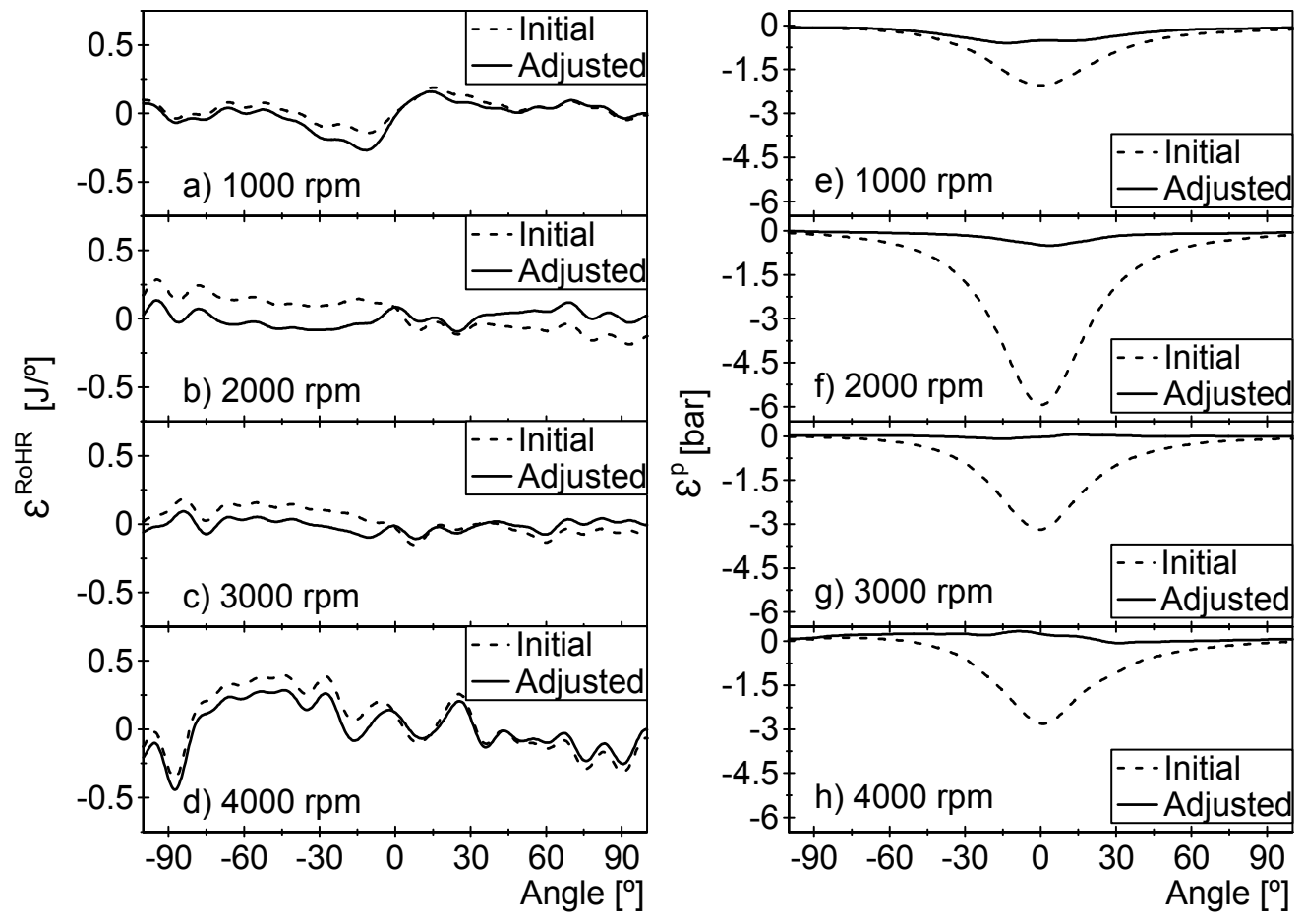

Figure 4: $\varepsilon^{R o H R}$ (left) and $\varepsilon^{p}$ (right) for the motoring measurement 

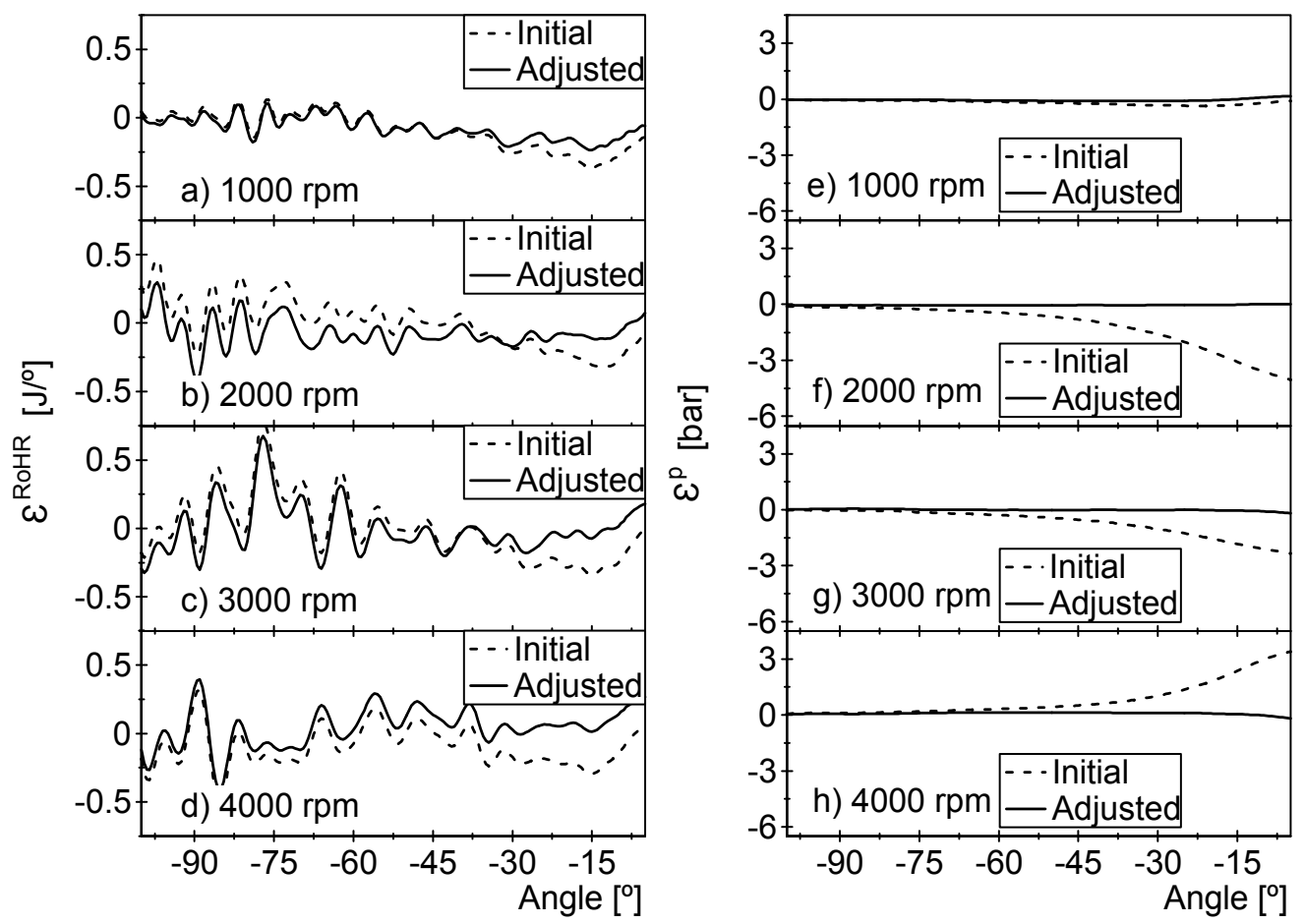

Figure 5: $\varepsilon^{R o H R}$ (left) and $\varepsilon^{p}$ (right) for the late SOI test

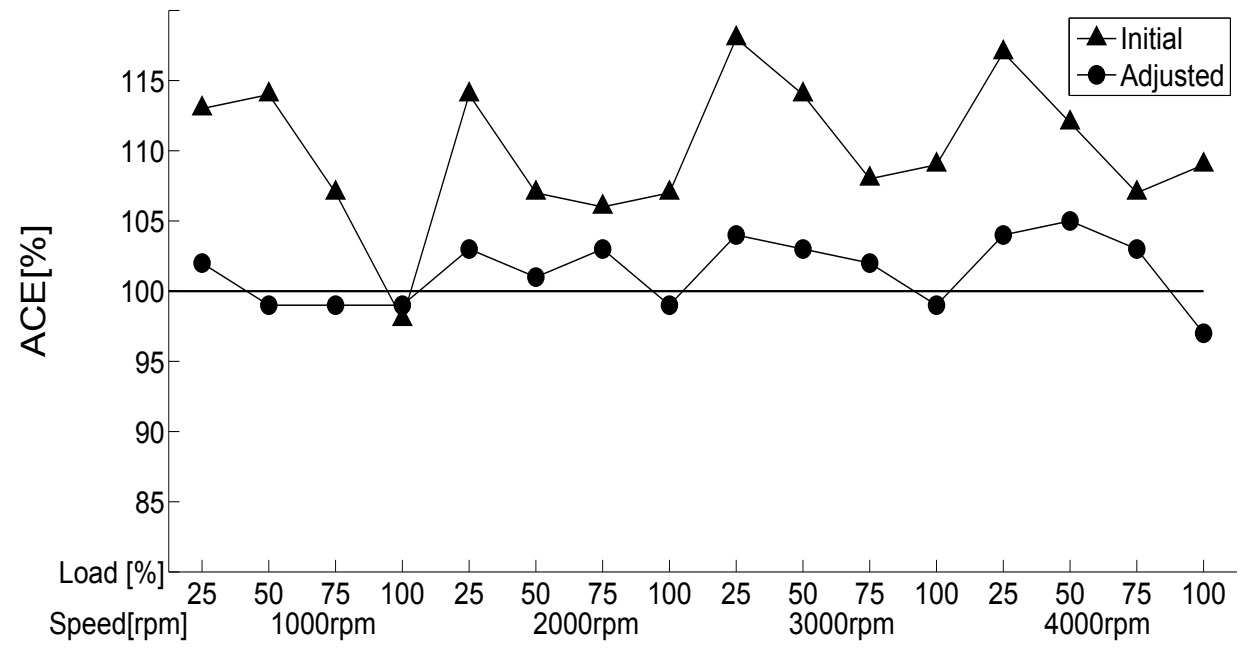

Figure 6: ACE of a set of combustion measurements using the initial and the adjusted parameters 

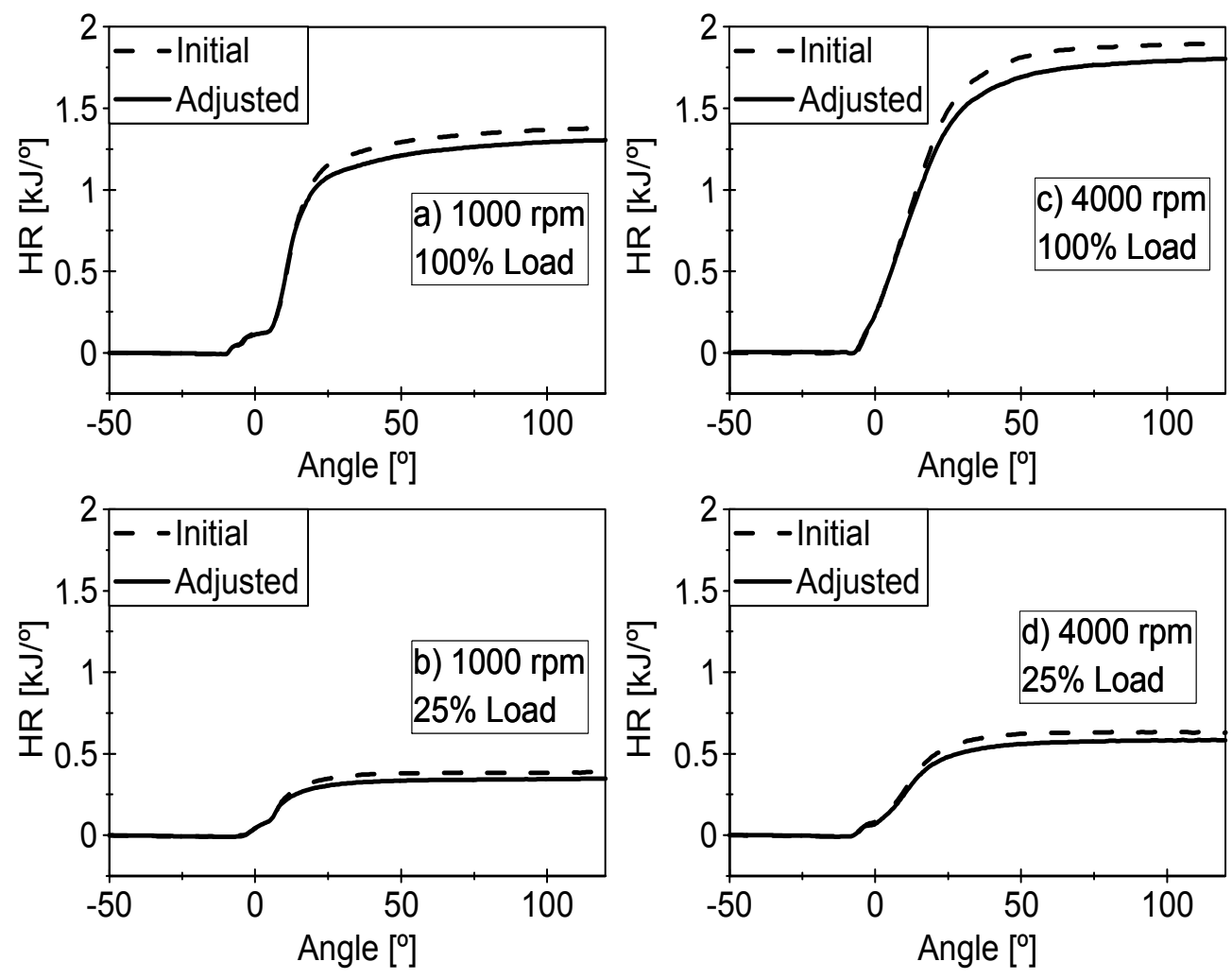

Figure 7: Cumulative HR with the initial parameters and the adjusted ones 


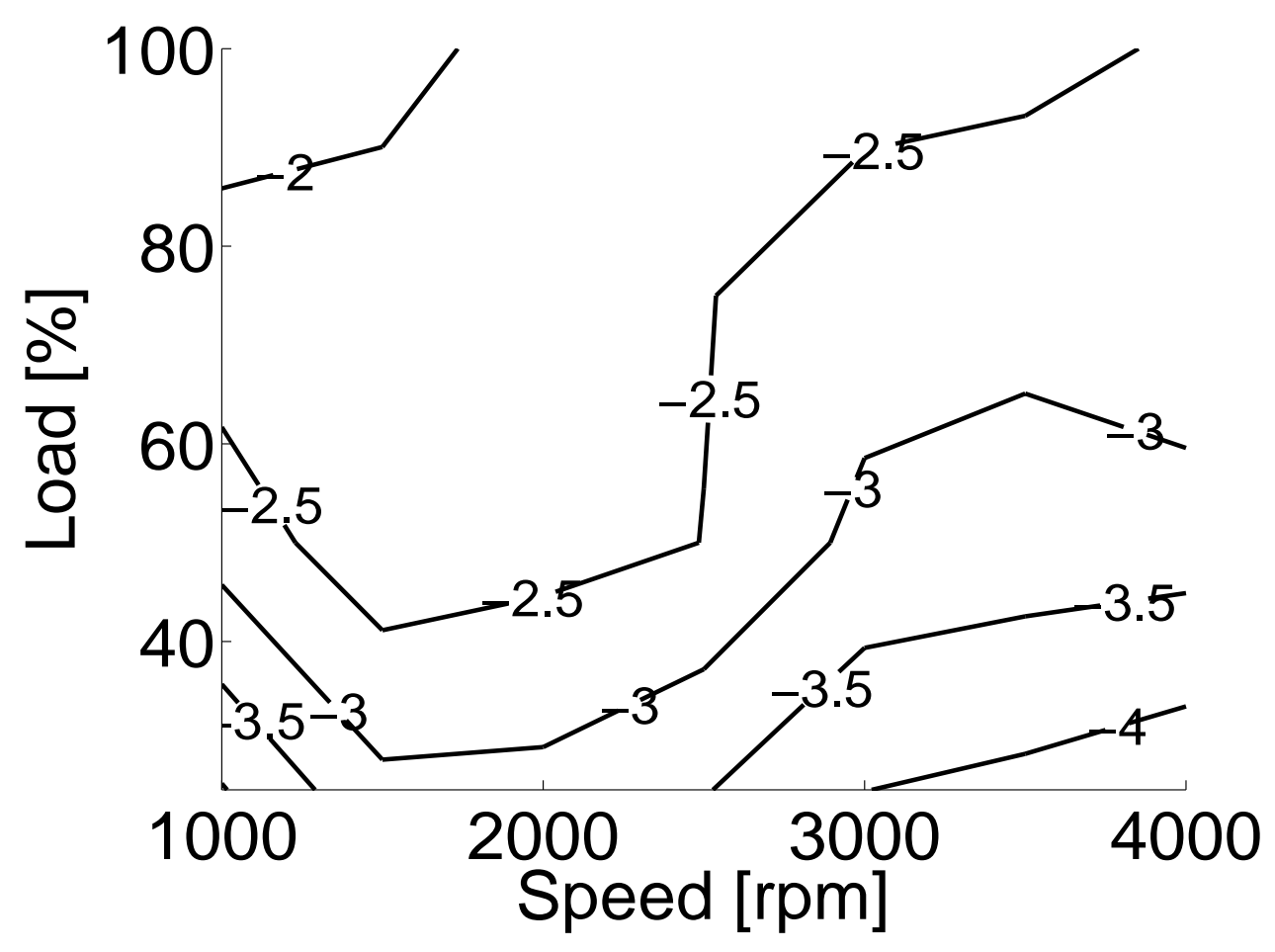

Figure 8: Indicated efficiency comparison between initial and adjusted parameters 


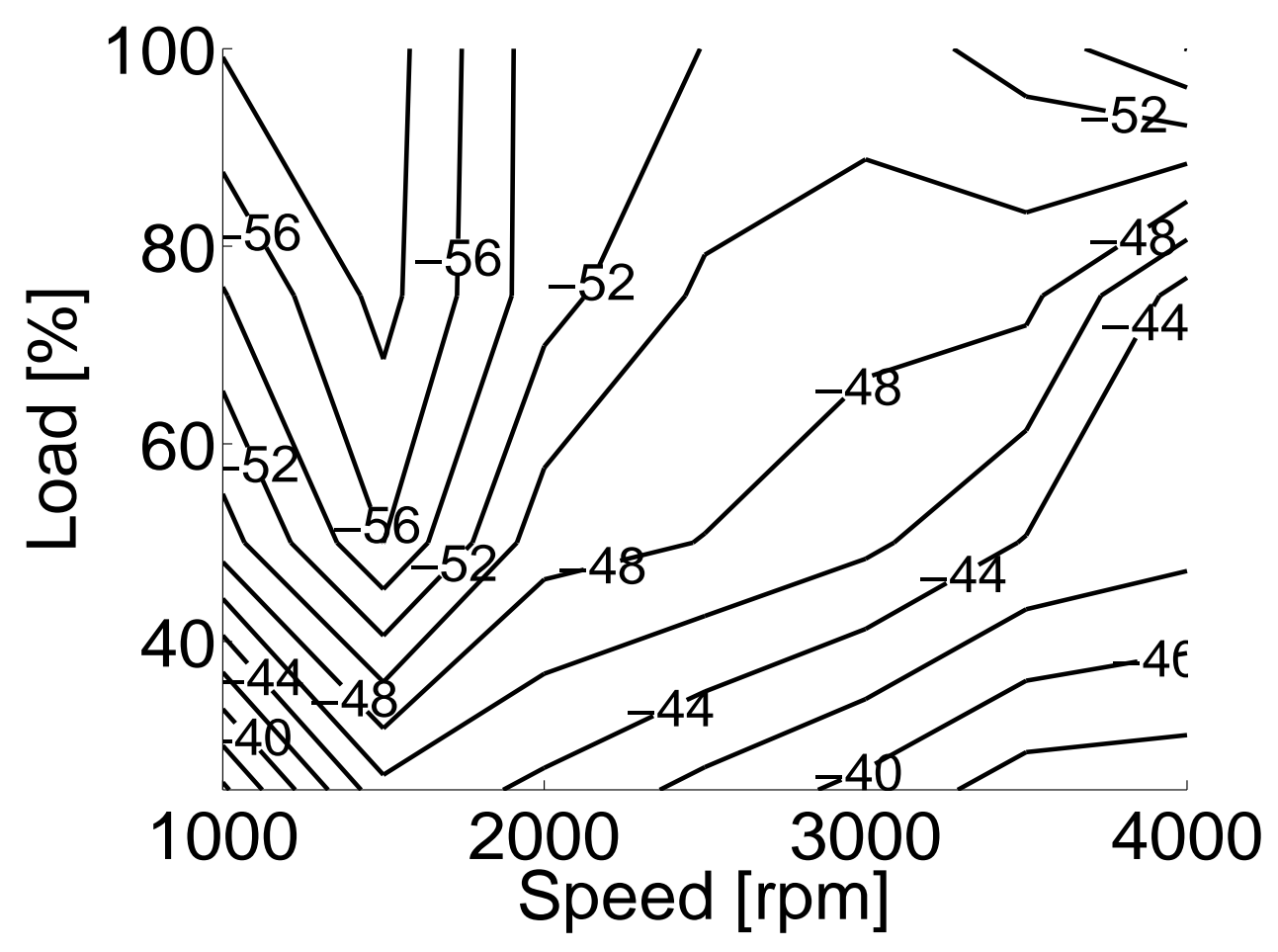

Figure 9: Maximum temperature deviations using initial and adjusted parameters 


\section{Tables}

Table 1. Tested engine characteristics.

Table 2. Parameter variations.

Table 3. Measured operational points.

Table 4. Adjustment of the tested engine.

Table 5. Error in RoHR and simulated $p_{\text {max }}$.

Table 1: Tested engine characteristics

\begin{tabular}{lc}
\hline Cylinders & 4 \\
Strokes & 4 \\
Bore & $75 \mathrm{~mm}$ \\
Stroke & $88 \mathrm{~mm}$ \\
Displacement & $390 \mathrm{~cm} 3$ \\
Nominal CR & $16: 1$ \\
\hline
\end{tabular}

Table 2: Parameter variations

\begin{tabular}{lc} 
Parameter & Variation \\
\hline $\mathrm{CR}$ & $\pm 0,75$ \\
$k_{\text {def }}$ & \pm 1 \\
$C_{W 1}$ & \pm 2 \\
$\Delta \alpha$ & $\pm 0,5^{\circ}$ \\
$p_{\text {ref }}$ & $\pm 100 \mathrm{mbar}$ \\
\hline
\end{tabular}




\begin{tabular}{ccc}
\multicolumn{3}{c}{ Table 3: Measured operational points } \\
Speed & Load & SOI \\
{$[\mathrm{rpm}]$} & {$[\%]$} & {$\left[{ }^{\circ}\right.$ ATDC $]$} \\
\hline 1000 & Motoring & - \\
1500 & Motoring & - \\
2000 & Motoring & - \\
2500 & Motoring & - \\
3000 & Motoring & - \\
3500 & Motoring & - \\
4000 & Motoring & - \\
1000 & 50 & 1,7 \\
2000 & 50 & 2,9 \\
3000 & 50 & 4,9 \\
4000 & 50 & 0,8 \\
\hline
\end{tabular}

Table 4: Adjustment of the tested engine

\begin{tabular}{ccccc} 
& Reference & Motoring & Delayed SOI 1 & Delayed SOI 2 \\
\hline $\mathrm{CR}$ & $16: 1$ & $15,9: 1$ & $15,4: 1$ & $15,9: 1$ \\
$k_{\text {def }}$ & 2,20 & 1,29 & 1,25 & 1,29 \\
$C_{W 1}$ & 2,28 & 1.74 & 0,65 & 2,04 \\
$\Delta \alpha$ & 369,0 & 369,9 & 369,6 & 369.9 \\
\hline
\end{tabular}

Table 5: Error in RoHR and simulated $p_{\max }$

\begin{tabular}{c|c|c|c|c} 
& \multicolumn{2}{|c|}{ RMSE of RoHR } & \multicolumn{2}{c}{ Error in $p_{\max }$} \\
\hline $\begin{array}{c}\text { Speed } \\
\mathrm{rpm}\end{array}$ & $\begin{array}{c}\text { Initial } \\
\mathrm{J} /{ }^{\circ}\end{array}$ & $\begin{array}{c}\text { Final } \\
\mathrm{J} /{ }^{\circ}\end{array}$ & $\begin{array}{c}\text { Initial } \\
\%\end{array}$ & $\begin{array}{c}\text { Final } \\
\%\end{array}$ \\
\hline 1000 & 0,09 & 0,11 & 5,5 & 1,1 \\
1500 & 0,17 & 0,13 & 9,0 & 0,5 \\
2000 & 0,10 & 0,07 & 8,9 & 0,8 \\
2500 & 0,15 & 0,11 & 8,7 & 0,8 \\
3000 & 0,10 & 0,06 & 8,7 & 0,8 \\
3500 & 0,14 & 0,07 & 9,0 & 0,7 \\
4000 & 0,21 & 0,17 & 8,7 & 0,5 \\
\hline
\end{tabular}

